\title{
Comparison of Different Turbulence Models for Numerical Simulation of Pressure Distribution in V-Shaped Stepped Spillway
}

\author{
Zhaoliang Bai and Jianmin Zhang \\ State Key Laboratory of Hydraulics and Mountain River Engineering, Sichuan University, Chengdu 610065, China \\ Correspondence should be addressed to Jianmin Zhang; zhangjianmin@scu.edu.cn
}

Received 23 March 2017; Accepted 1 August 2017; Published 7 September 2017

Academic Editor: Alistair Borthwick

Copyright (c) 2017 Zhaoliang Bai and Jianmin Zhang. This is an open access article distributed under the Creative Commons Attribution License, which permits unrestricted use, distribution, and reproduction in any medium, provided the original work is properly cited.

\begin{abstract}
V-shaped stepped spillway is a new shaped stepped spillway, and the pressure distribution is quite different from that of the traditional stepped spillway. In this paper, five turbulence models were used to simulate the pressure distribution in the skimming flow regimes. Through comparing with the physical value, the realizable $k-\varepsilon$ model had better precision in simulating the pressure distribution. Then, the flow pattern of $\mathrm{V}$-shaped and traditional stepped spillways was given to illustrate the unique pressure distribution using realizable $k-\varepsilon$ turbulence model.
\end{abstract}

\section{Introduction}

The unique structure of the stepped spillways causes abundant vortices near the steps [1-3], which results in high energy dissipation and aeration than that of smooth spillways $[4,5]$. For these reasons, the stepped spillways have been widely used $[6,7]$.

Considering that the flow pattern of the stepped spillway reflects the hydraulic characteristics of the flow, many scholars have also studied the flow regimes. The flow regimes of a stepped spillway can be divided into nappe flow, transition flow, and skimming flow [8-10]. Pressure distribution in stepped spillways also became a research focus for negative pressure on the step surface which may lead to cavitation damage. Many scholars have studied the pressure distributions of stepped spillways through physical models, such as Zhang et al. [11], Fratino et al. [12], Sánchez-Juny et al. [13, 14], Amador et al. [15], Zhang et al. [16], and Dhatrak and Tatewar [17] and so on. With the development of computer science and computational technology, the numerical method has become an efficient method to study the pressure distribution of stepped spillways. Chen et al. [2] studied the pressure distribution of traditional stepped spillway using $k-\varepsilon$ turbulence model and satisfactory results were obtained. Qian et al.
[18] compared four turbulence models (realizable $k-\varepsilon$ model, SST $k$ - $\varepsilon$ model, $v^{2}-f$ model and LES model) and found that the realizable $k-\varepsilon$ model was the most efficient in simulating flow overstepped spillways which involves rotation. And the pressure field was studied using the realizable $k-\varepsilon$ model. Chakib [19] also got the contours of pressure distribution in simulating air-water interaction using $k-\varepsilon$ turbulence model and VOF model. Daneshfaraz et al. [20] adopted standard $k-\varepsilon$, renormalization group $k-\varepsilon$, and standard $k$ $\omega$ turbulence model to simulate the four step arrangements stepped spillways. And pressure distribution was studied by RNG $k-\varepsilon$ turbulence model, which was regarded as the optimal turbulence model through comparing the physical value and numerical value of water level.

In this paper, the stepped spillways of $\theta=120^{\circ}$ and $\theta=$ $180^{\circ}$ are named as $\mathrm{V}$-shaped and traditional stepped spillway, respectively (shown in Figure 1). V-shaped stepped spillway is a new type of stepped spillways, which has distinguished three-dimensional flow program and greater aerated characteristic. In this paper, the pressure distribution along the Vshaped stepped spillway in the skimming flow regime was studied through numerical simulations with five kinds of turbulence models and the unique pressure distribution was 
analyzed through the comparison of the flow pattern between traditional and V-shaped stepped spillways. These results can be used to choose a better turbulence model to study the pressure distribution of $\mathrm{V}$-shaped stepped spillway.

\section{Numerical Simulation}

Fluent software was used to perform these simulations using the finite volume method (FVM). The numerical model of the stepped spillway (shown in Figure 1) consists of a press slope section, a smooth section, a stepped section, and tail water section. The chute width is $B=0.4 \mathrm{~m}$, the height of the model inlet is $h=0.12 \mathrm{~m}$, and the outlet of the press slope section is $0.08 \mathrm{~m}$. The step section consists of 56 steps, which were numbered \#1 to \#56. The first 28 steps are transitional steps for improving the flow patterns; then there are 28 uniform steps ( $6 \mathrm{~cm}$ high, $12 \mathrm{~cm}$ long). The slope of the stepped spillway is $1 \mathrm{~V}: 2 \mathrm{H}$.

2.1. Fluid Volume Model. The volume of fluid (VOF) was used to track the air-water interface, which was presented by Hirt and Nichols [21]. In each computational cell, the sum of the volume fractions of air, $\alpha_{a}$, and water, $\alpha_{w}$, is unity and can be given as

$$
\alpha_{w}+\alpha_{a}=1 ; \quad 0 \leq \alpha_{w}, \alpha_{a} \leq 1
$$

In this approach, the tracking interface between air and water was accomplished by the solution of the continuity equation for the volume fraction of water:

$$
\frac{\partial \alpha_{w}}{\partial t}+\frac{\partial \alpha_{w} u_{i}}{\partial x_{i}}=0
$$

\subsection{Turbulence Models}

2.2.1. ST $k$ - $\varepsilon$ Model for the VOF Flow. The standard (ST) $k-\varepsilon$ turbulence model presented by Launder and Spalding [22] was useful in practical engineering flow calculations for the advantages of economy and reasonable accuracy. The equations of turbulent kinetic energy, $k$, and its dissipation rate, $\varepsilon$, are as follows:

$$
\begin{aligned}
\frac{\partial(\rho k)}{\partial t}+\frac{\partial}{\partial x_{i}}\left(\rho k u_{i}\right)= & \frac{\partial}{\partial x_{j}}\left[\left(\mu+\frac{\mu_{t}}{\sigma_{k}}\right) \frac{\partial k}{\partial x_{j}}\right]+G_{k} \\
& +G_{b}-\rho \varepsilon-Y_{M}+S_{k} \\
\frac{\partial(\rho \varepsilon)}{\partial t}+\frac{\partial}{\partial x_{i}}\left(\rho \varepsilon u_{i}\right)= & \frac{\partial}{\partial x_{j}}\left[\left(\mu+\frac{\mu_{t}}{\sigma_{\varepsilon}}\right) \frac{\partial \varepsilon}{\partial x_{j}}\right] \\
& +C_{1 \varepsilon} \frac{\varepsilon}{k}\left(G_{k}+C_{3 \varepsilon} G_{b}\right) \\
& -C_{2 \varepsilon} \rho \frac{\varepsilon^{2}}{k}+S_{\varepsilon},
\end{aligned}
$$

where $G_{k}, G_{b}$ are the generation of turbulence kinetic energy due to the mean velocity gradients and buoyancy, respectively; $Y_{M}$ is the contribution of the fluctuating dilatation in compressible turbulence to the overall dissipation rate; $u_{i}$ is the mean velocity component in the $i$ th direction; $\mu_{t}$ is the turbulent viscosity and calculated by $\mu_{t}=\rho C_{\mu}\left(k^{2} / \varepsilon\right) ; C_{\mu}, C_{1 \varepsilon}$, $C_{2 \varepsilon}, \sigma_{k}$, and $\sigma_{\varepsilon}$ are model constants which are specified as follows: $C_{\mu}=0.09, C_{1 \varepsilon}=1.44, C_{2 \varepsilon}=1.92, \sigma_{k}=1.0$, and $\sigma_{\varepsilon}=$ 1.3. $S_{k}$ and $S_{\varepsilon}$ are user-defined source terms.

This model is a semiempirical model based on transport equations for turbulence kinetic energy and turbulence kinetic energy dissipation rate. For its assumption of fully turbulent, it is valid only for fully turbulent flows.

2.2.2. RNG $k-\varepsilon$ Model for the VOF Flow. The renormalization group (RNG) $k-\varepsilon$ turbulence model was presented by Yakhot and Orszag [23]. The equations of turbulent kinetic energy, $k$, and its dissipation rate, $\varepsilon$, are as follows:

$$
\begin{aligned}
\frac{\partial(\rho k)}{\partial t}+\frac{\partial}{\partial x_{i}}\left(\rho u_{i} k\right)= & \frac{\partial}{\partial x_{j}}\left[\alpha_{k} \mu_{\mathrm{eff}} \frac{\partial k}{\partial x_{j}}\right]+G_{k}+G_{b} \\
& -\rho \varepsilon-Y_{M}+S_{k} \\
\frac{\partial(\rho \varepsilon)}{\partial t}+\frac{\partial}{\partial x_{i}}\left(\rho u_{i} \varepsilon\right)= & \frac{\partial}{\partial x_{j}}\left[\alpha_{\varepsilon} \mu_{\mathrm{eff}} \frac{\partial \varepsilon}{\partial x_{j}}\right] \\
& +C_{1 \varepsilon} \frac{\varepsilon}{k}\left(G_{k}+C_{3 \varepsilon} G_{b}\right) \\
& -C_{2 \varepsilon} \rho \frac{\varepsilon^{2}}{k}-R_{\varepsilon}+S_{\varepsilon}
\end{aligned}
$$

where $\alpha_{k}, \alpha_{\varepsilon}$ are the inverse effective Prandtl numbers; $C_{1 \varepsilon}$ $=1.42, C_{2 \varepsilon}=1.68$ are model constants; $R_{\varepsilon}=C_{\mu} \rho \eta^{3}(1-$ $\left.\eta / \eta_{0}\right) \varepsilon^{2} /\left(k\left(1+\beta \eta^{3}\right)\right)$, where $\eta \equiv S k / \varepsilon, \eta_{0}=4.38$, and $\beta=0.012$.

This model was derived using a rigorous statistical technique. Although it is similar in form to the ST $k-\varepsilon$ turbulence model, there are some refinements: (1) adding an additional term in turbulence kinetic energy dissipation rate equation which improves the accuracy for rapidly strained flows; (2) the effect of swirl is included to enhance accuracy for swirling flows; (3) the turbulent Prandtl numbers are got by analytical formula.

2.2.3. $R l k-\varepsilon$ Model for the VOF Flow. The realizable (Rl) $k$ $\varepsilon$ turbulence model was presented by Shih et al. [24]. The equations of turbulent kinetic energy, $k$, and its dissipation rate, $\varepsilon$, are as follows:

$$
\begin{aligned}
\frac{\partial(\rho k)}{\partial t}+\frac{\partial}{\partial x_{j}}\left(\rho u_{j} k\right)= & \frac{\partial}{\partial x_{j}}\left[\left(\mu+\frac{\mu_{t}}{\sigma_{k}}\right) \frac{\partial k}{\partial x_{j}}\right]+G_{k} \\
& +G_{b}-\rho \varepsilon-Y_{M}+S_{k} \\
\frac{\partial(\rho \varepsilon)}{\partial t}+\frac{\partial}{\partial x_{j}}\left(\rho u_{j} \varepsilon\right)= & \frac{\partial}{\partial x_{j}}\left[\left(\mu+\frac{\mu_{t}}{\sigma_{\varepsilon}}\right) \frac{\partial \varepsilon}{\partial x_{j}}\right] \\
& +\rho C_{1} S_{\varepsilon}-\rho C_{2} \frac{\varepsilon^{2}}{k+\sqrt{\nu \varepsilon}} \\
& +C_{1 \varepsilon} \frac{\varepsilon}{k} C_{3 \varepsilon} G_{b}+S_{\varepsilon}
\end{aligned}
$$




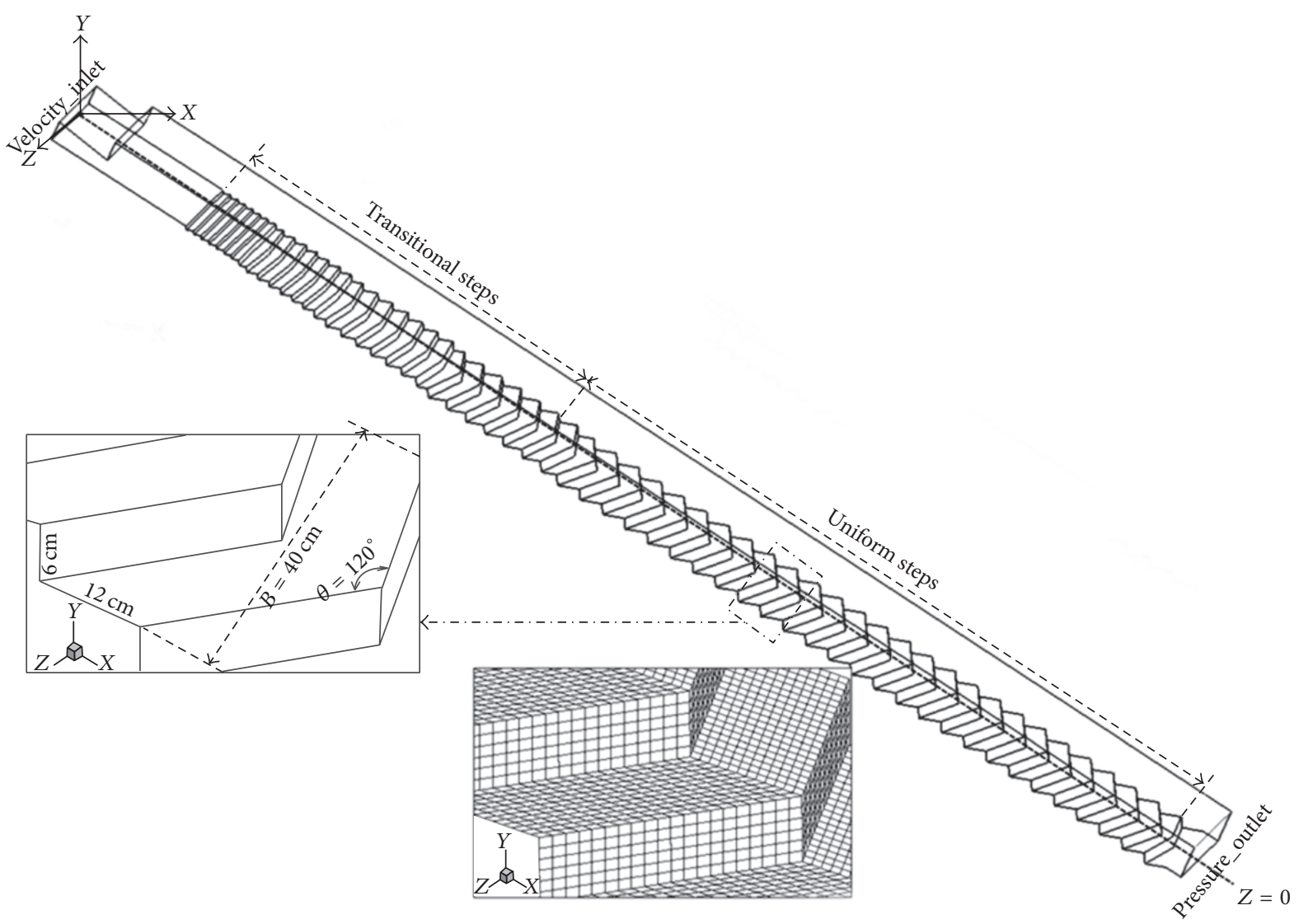

FIGURE 1: The numerical model layout.

where $C_{1}=\max [0.43, \eta /(\eta+5)]$ and $\eta=S k / \varepsilon, S=$ $\sqrt{2 S_{i j} S_{i j}}$, where $S_{i j}=0.5\left(\partial u_{j} / \partial x_{i}+\partial u_{i} / \partial x_{j}\right) ; \nu$ is the turbulent kinematic viscosity; $C_{1 \varepsilon}=1.44, C_{2}=1.9, \sigma_{k}=1.0$, and $\sigma_{\varepsilon}=1.2$ are the empirical constants.

This model can accurately simulate the spreading rate of both planar and round jets and the flows involving rotation, boundary layers under strong adverse pressure gradients, separation, and recirculation.

2.2.4. ST k- $\omega$ Model for the VOF Flow. The standard (ST) $k$ - $\omega$ turbulence model was presented by Wilcox [25], which incorporates modifications for low-Reynolds-number effects, compressibility, and shear flow spreading. The equations of turbulent kinetic energy, $k$, and its dissipation rate, $\omega$, are as follows:

$$
\begin{gathered}
\frac{\partial(\rho k)}{\partial t}+\frac{\partial}{\partial x_{i}}\left(\rho u_{i} k\right)=\frac{\partial}{\partial x_{j}}\left(\Gamma_{k} \frac{\partial k}{\partial x_{j}}\right)+G_{k}-Y_{k}+S_{k} \\
\frac{\partial(\rho \omega)}{\partial t}+\frac{\partial}{\partial x_{i}}\left(\rho u_{i} \omega\right)= \\
\frac{\partial}{\partial x_{j}}\left(\Gamma_{\omega} \frac{\partial \omega}{\partial x_{j}}\right)+G_{\omega}-Y_{\omega} \\
+S_{\omega},
\end{gathered}
$$

where $G_{\omega}$ is the generation of $\omega ; \Gamma_{k}$ and $\Gamma_{\omega}$ are the effective diffusivity of $k$ and $\omega$, respectively; $Y_{k}$ and $Y_{\omega}$ are the dissipation of $k$ and $\omega$, respectively; $S_{\omega}$ is the user-defined source term.
This model is an empirical model based on model transport equations for the turbulence kinetic energy and turbulence kinetic energy dissipation rate.

2.2.5. SST $k-\omega$ Model for the VOF Flow. The shear-stress transport (SST) $k-\omega$ turbulence model was developed by Menter [26]. The equations of turbulent kinetic energy, $k$, and its dissipation rate, $\omega$, are as follows:

$$
\begin{aligned}
\frac{\partial(\rho k)}{\partial t}+\frac{\partial}{\partial x_{i}}\left(\rho u_{i} k\right)= & \frac{\partial}{\partial x_{j}}\left(\Gamma_{k} \frac{\partial k}{\partial x_{j}}\right)+G_{k}-Y_{k}+S_{k} \\
\frac{\partial(\rho \omega)}{\partial t}+\frac{\partial}{\partial x_{i}}\left(\rho u_{i} \omega\right)= & \frac{\partial}{\partial x_{j}}\left(\Gamma_{\omega} \frac{\partial \omega}{\partial x_{j}}\right)+G_{\omega}-Y_{\omega} \\
& +D_{\omega}+S_{\omega},
\end{aligned}
$$

where $D_{\omega}$ is the cross-diffusion term.

\subsection{Boundary Conditions}

(1) Inlet Boundary. At the inlet, velocity inlet was used and the velocity was $2.61-4.08 \mathrm{~m} / \mathrm{s}$ according to the unit discharges;

(2) Outlet Boundary. At the outlet, the pressure outlet boundary was chosen and the normal gradient of all variables were 0 . 


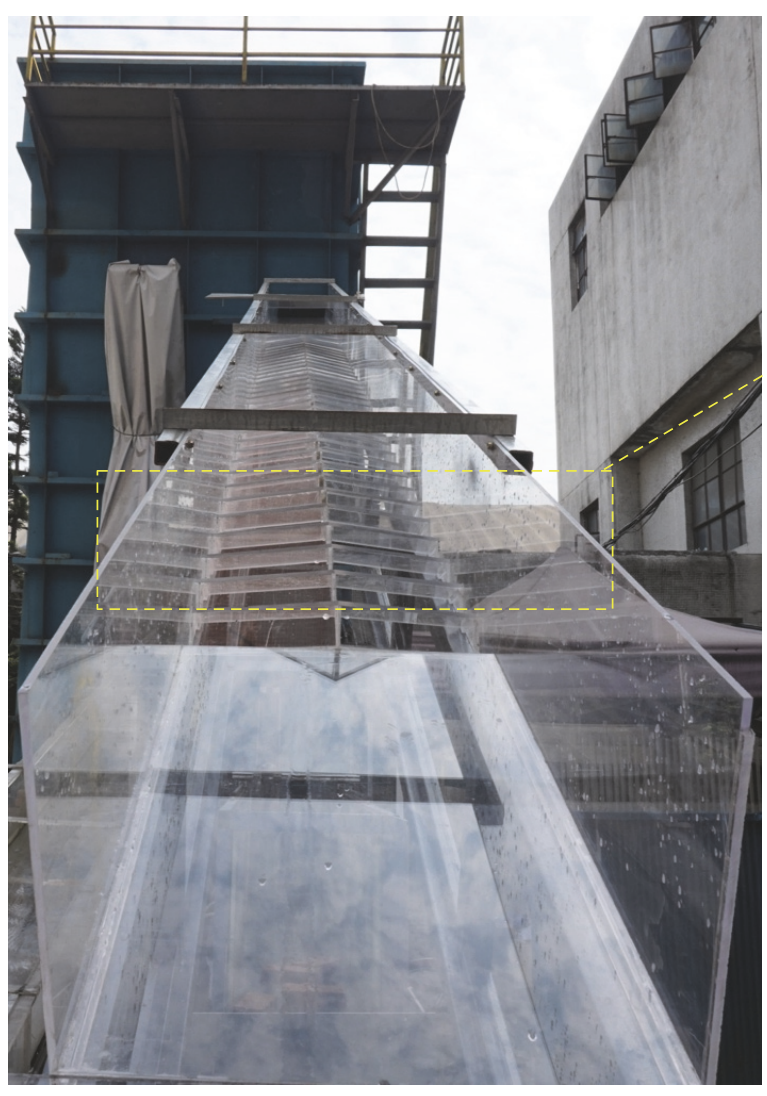

(a)

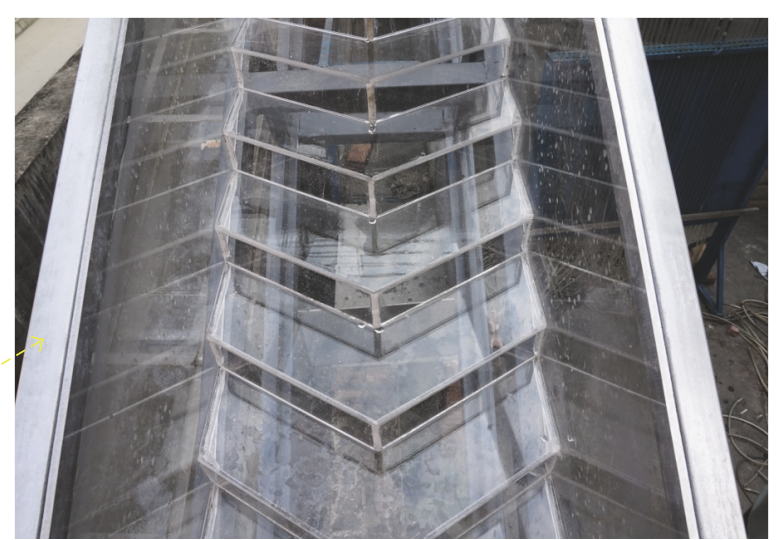

(b)

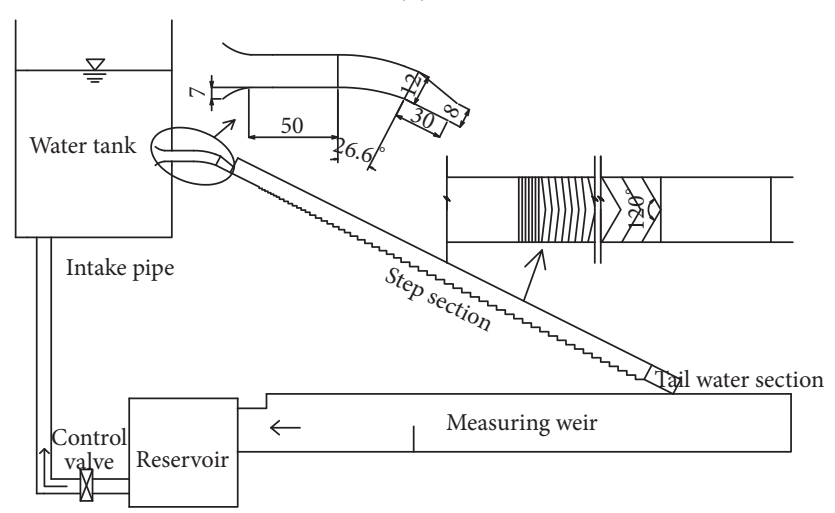

(c)

FIGURE 2: The physical model layout.

(3) Free Surface. Pressure inlet was presented at the free surface;

(4) Wall Boundary. The no-slip velocity boundary condition was used on the wall surface and the standard wall function was chosen to specify the near-wall regions of the flow.

2.4. Validation Model. A physical model of V-shaped stepped spillway is shown in Figure 2, which was performed in the State Key Laboratory of Hydraulics and Mountain River Engineering, Sichuan University, Chengdu. The total model height was $5.4 \mathrm{~m}$ and the size of the stepped spillway was identical to that in the numerical model, as shown in Figure 1. Piezometer tube was used to measure the time-averaged pressure.

\section{Results and Analysis}

3.1. Pressure Distribution. Figure 3 shows the pressure distribution on steps, where $L$ represents the width of the step and $H$ represents the height of the step. The figure shows that (1) for traditional stepped spillway, the pressure does not change along the cross section, but there are obvious changing at different profiles of $\mathrm{V}$-shaped stepped spillway; (2) the extreme values of pressure locate at the sidewalls in V-shaped stepped spillway, but they locate along the cross section in traditional stepped spillway; (3) the maximum pressure on horizontal step surface of V-shaped stepped spillway is larger than that of on traditional stepped spillway and the minimum pressure on vertical step surface of $\mathrm{V}$ shaped stepped spillway is smaller than that of on traditional stepped spillway.

3.2. Pressure Distribution of the Profiles. Since the pressure distribution changed along the cross section in V-shaped stepped spillway, three rows of pressure measurement points were adopted, and the position of rows was in $Z / B=0, Z / B$ $=0.25$, and near the $Z / B=0.5$, respectively. The interval of pressure measurement points was $1 \mathrm{~cm}$ in each row, which means that each step horizontal surface had 11 points and 5 points on vertical surface in each row, as shown in Figure 4.

In this section, we take the pressure distribution on one step $(\# 43)$ when $\mathrm{Fr}=5.99$ as an example to illustrate. Figure 5 shows the pressure distributions of physical model and five turbulence models on \#43 step. Note from Figure 5 that (1) the numerical values at all pressure measurement points show a good agreement with the physical values at each profile; (2) it also can be regarded as an S-shaped variation on horizontal step surface, but the fluctuation decreases from both sidewalls to the axial plane; (3) on vertical step surface, from the step's lower edge to its upper edge $(Y / H=1.0)$, the pressure gradually decreases at all the profiles and at the same step height, from the axial plane to sidewalls, 

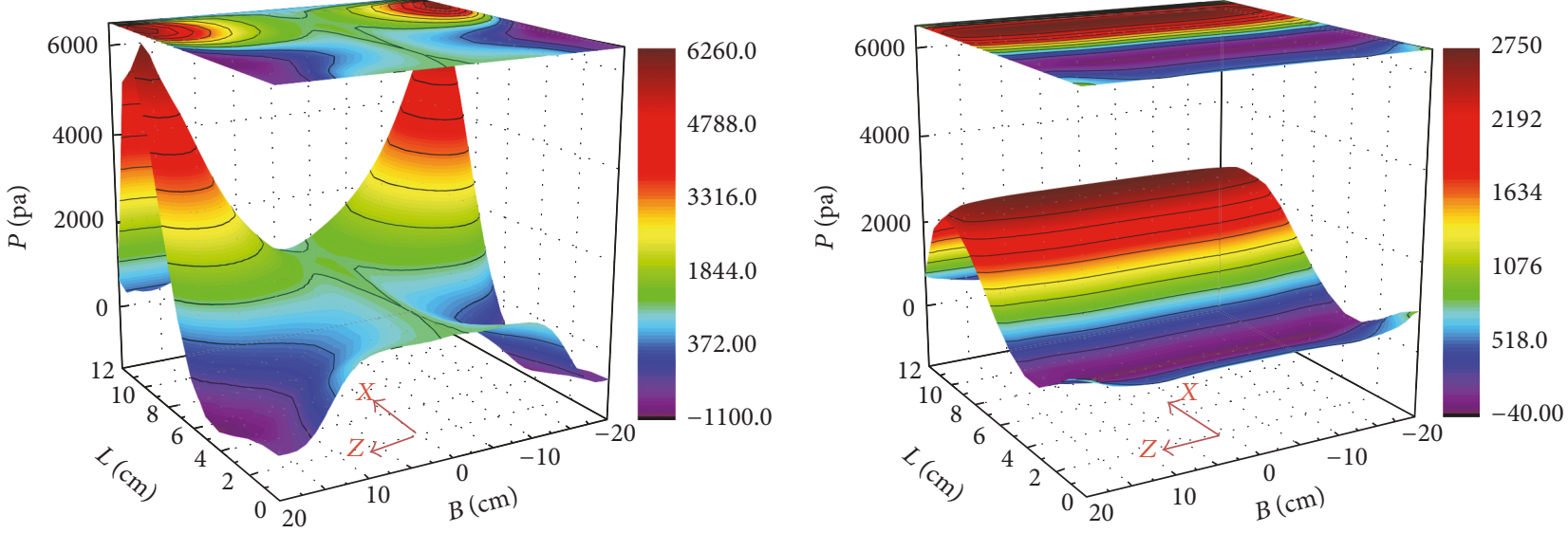

Horizontal surface

Horizontal surface
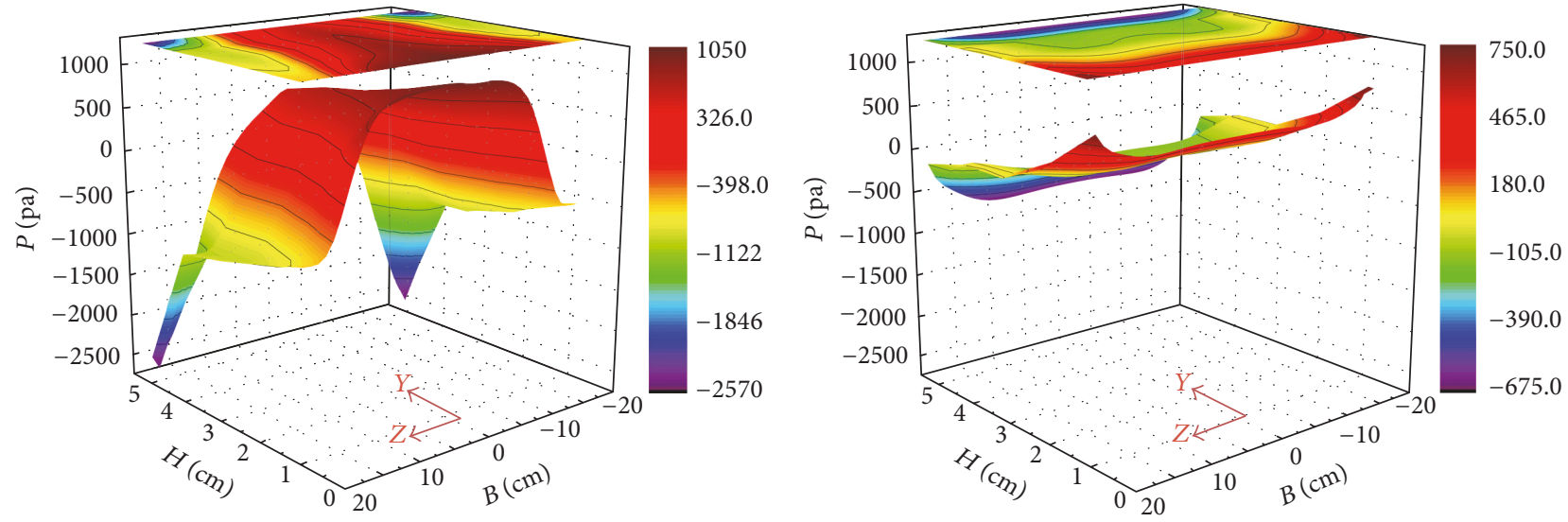

Vertical surface

Vertical surface

(a)

(b)

FIGURE 3: The pressure distribution on steps ((a) on V-shaped step, (b) on traditional step).

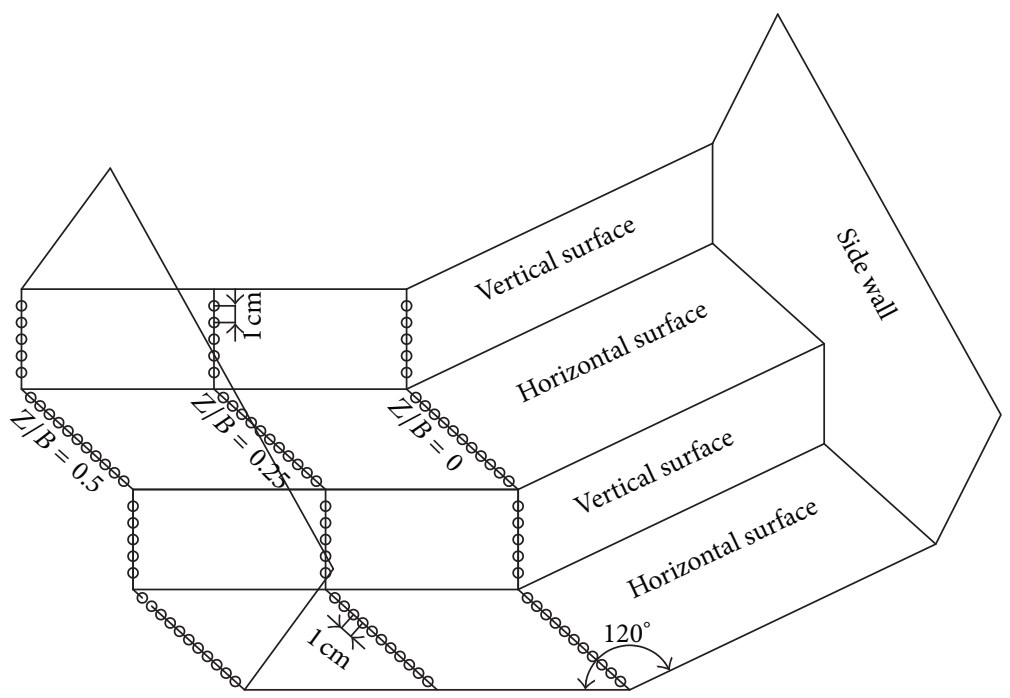

Figure 4: Pressure measurement points on steps. 


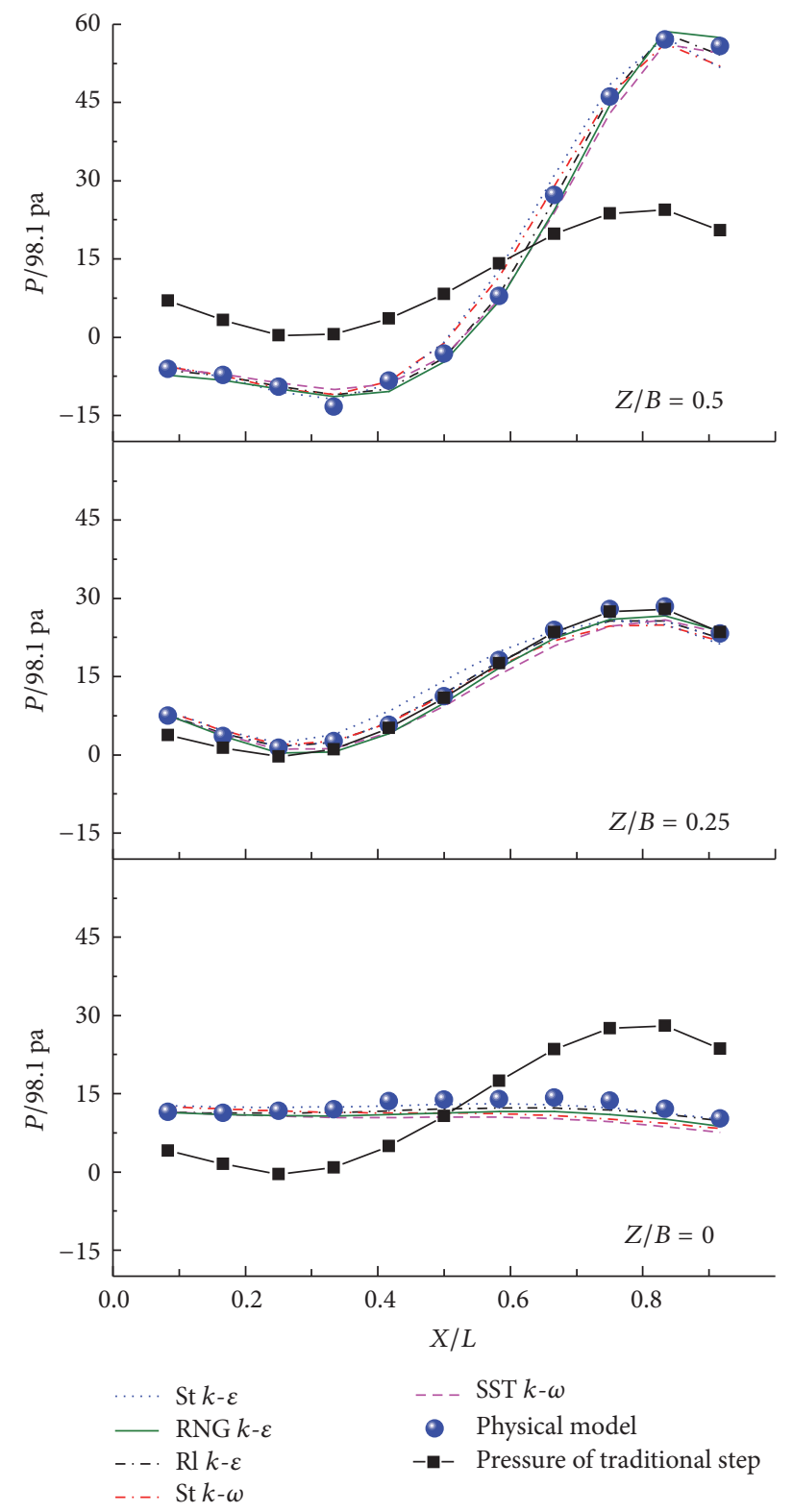

(a)

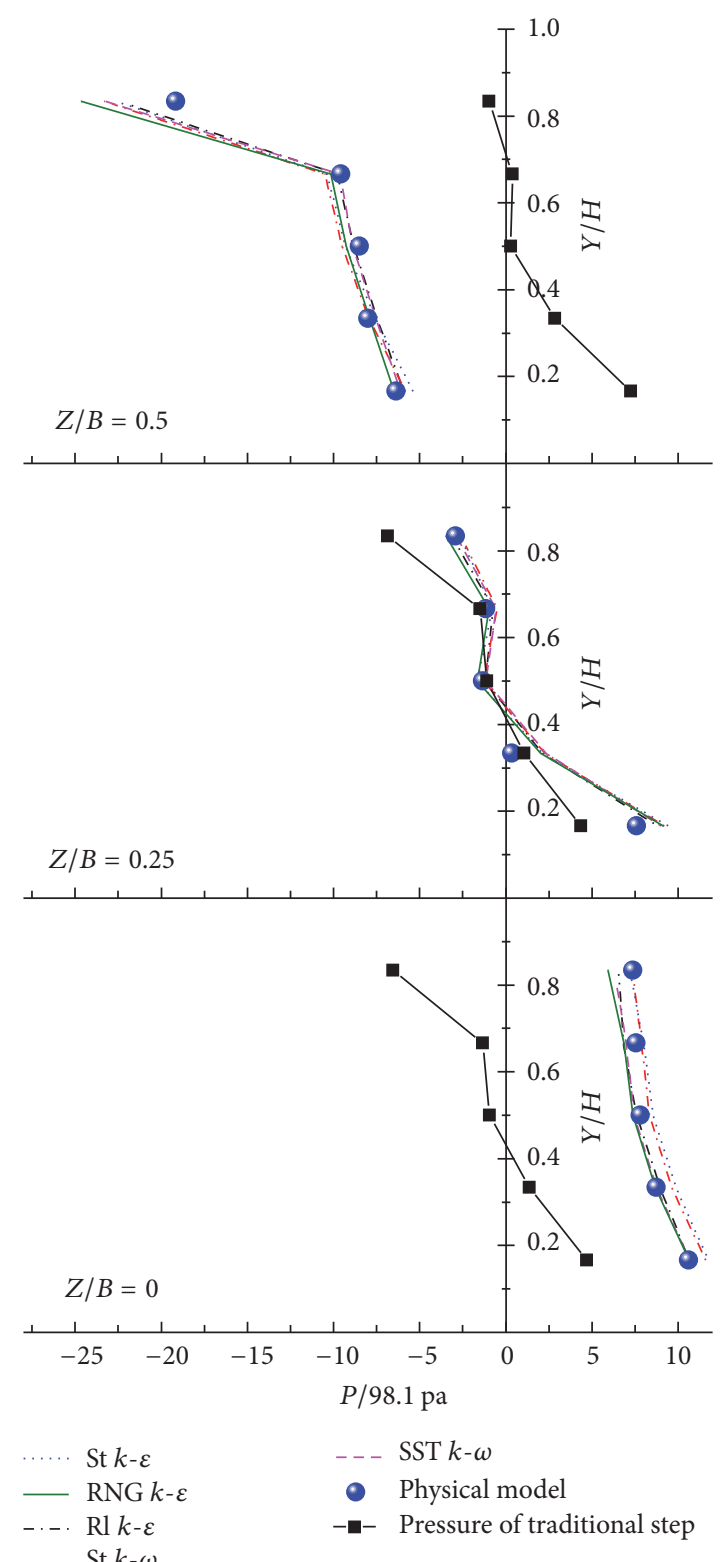

(b)

Figure 5: The pressure distribution of profiles on step ((a) on horizontal surface, (b) on vertical surface, $\mathrm{Fr}=5.997)$.

pressure also gradually decreases; (4) at $Z / B=0.25$, the pressure distributions of $\mathrm{V}$-shaped and traditional stepped spillways are nearly the same; from the profile of $Z / B=$ 0.25 to sidewalls, the fluctuation of pressure distribution is larger on the horizontal step surface and the pressure is lower at the same position on vertical step surface than those of in traditional stepped spillway; otherwise, from the profile of $Z / B=0.25$ to axial plane, the fluctuation of pressure distribution is smaller on the horizontal step surface and the pressure is larger at the same position on the vertical step surface than those of in traditional stepped spillway; finally, at $Z / B=0$, the pressure is nearly the same on the horizontal step surface and the pressure is positive on the vertical step surface.
For comparing the turbulence models performance statistically, the root mean square error (RMSE) criterion was estimated using

$$
\mathrm{RMSE}=\sqrt{\frac{1}{n} \sum_{1}^{n}\left(\text { Pressure }_{\text {physical }}-\text { Pressure }_{\text {numerical }}\right)^{2}}
$$

where $n$ is the number of pressure measurement points in each profile, pressure $_{\text {physical }}$ and pressure ${ }_{\text {numerical }}$ are the physical and numerical values of the pressure, respectively. According to the definition of RMSE, the lower the RMSE value is, the more accurate the model is. 
TABLE 1: The RMSE values of different turbulence models.

\begin{tabular}{lcccccc}
\hline Step surface & Profile & St $k-\varepsilon$ & RNG $k-\varepsilon$ & Rl $k-\varepsilon$ & St $K-\omega$ & 2.25 \\
Horizontal surface & $Z / B=0$ & 0.98 & 1.93 & 1.30 & 1.20 & 1.71 \\
& $Z / B=0.25$ & 2.00 & 1.39 & 1.63 & 1.11 & 1.98 \\
\hline \multirow{3}{*}{ Vertical surface } & $Z / B=0.5$ & 2.56 & 0.75 & 0.53 & 0.67 & 1.93 \\
& $Z / B=0$ & 1.15 & 1.06 & 0.99 & 1.15 & 0.59 \\
& $Z / B=0.25$ & 1.70 & 2.49 & 1.51 & 1.96 \\
\hline
\end{tabular}

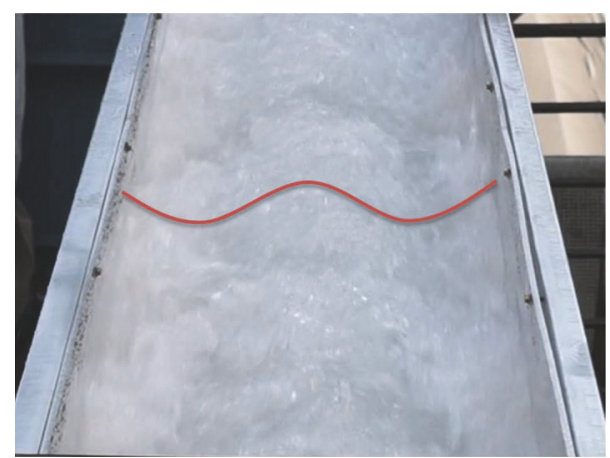

(a)

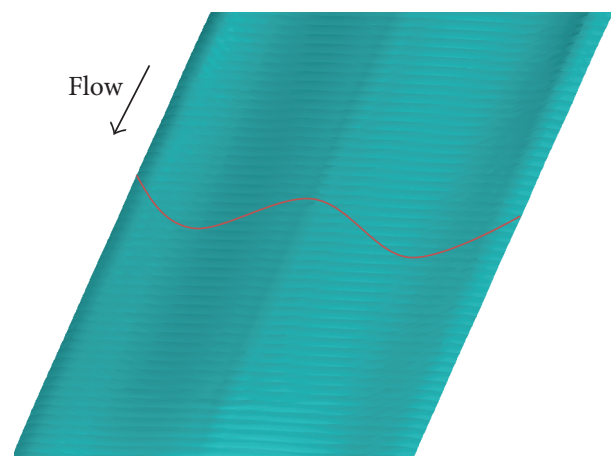

(b)

FIGURE 6: The free water surface of physical model and numerical model ((a) physical model, (b) Rl $k-\varepsilon$ model).

Table 1 presents the RMSE values of five turbulence models. It can be seen that (1) all the numerical turbulence models show satisfactory results at each profile; (2) the Rl $k$ $\varepsilon$ model can be regarded as a better model to simulate the pressure distribution of $\mathrm{V}$-shaped stepped spillway according all the RMSE values.

3.3. The Flow Pattern. Figure 6 is the free water surface of the physical model and numerical model. It can be seen that (1) the results of the free water surfaces of numerical model and physical model are similar; (2) the free water surfaces of the axial plane and near sidewall were higher, and it is lower in other places, like a "W" shape, which is different from that of the traditional stepped spillway.

For stepped spillway, when the flow transitions from one step to the next step, a part of the flow travels in the downstream direction, and the other part changes direction because of the collision between the water and the steps. The flow that changes direction forms a reflux and collides with the vertical step surface. Then, the flow is forced to climb and blocked by the mainstream, forming stable vortices.

To clearly show the spiral flow and downstream flow, the streamlines are shown in different steps in Figure 7(d). From Figure 7(a), we can see that the velocity vectors are parallel to the axial plane, so the vortices are parallel to the axial plane (as shown in Figure 7(c)) and the flow pattern can be regarded as a two-dimensional flow, so the pressure distribution of traditional stepped spillway does not change along the cross section. However, from Figure 7(b), we can see that the velocity vectors are not parallel to the axial plane in V-shaped stepped spillway, and there is transverse velocity which is from the sidewall to the axial plane. So the water is nearly void at the sidewalls and causes the minimum pressure at the upper ledge of vertical step surface at sidewall profiles. And the collision is formed through the vortex flow from the sidewall to the axial plane at near the axial plane, so the water surface is high at near the axial plane and the flow pattern can be regarded as a three-dimensional flow (as shown in Figure $7(\mathrm{~d})$ ). For this kind of unique flow field, the pressure distribution of V-shaped stepped spillway is obviously different at different profiles.

This flow field in V-shaped stepped spillway increases the turbulence intensity; therefore, there will be better energy dissipation rate and aeration properties and this will be studied in the future.

\section{Conclusions}

In this paper, the pressure distribution of V-shaped stepped spillway was studied using five turbulence models. The following conclusions can be drawn:

(1) Although all the numerical results show a good agreement with physical values, the realizable $k-\varepsilon$ model is slightly better than other turbulence models in simulating the pressure distribution of V-shaped stepped spillway.

(2) Compared to traditional steps, the negative pressure is greater than the traditional steps, but the order of magnitude has not changed. So near the sidewalls, compared to the Vshaped steps, although the traditional steps are more resistant to cavitation damage, there is no obvious difference between them. Considering better energy dissipation rate and aeration properties, there are broad application prospects, especially in ecological water conservancy and aeration tanks. 


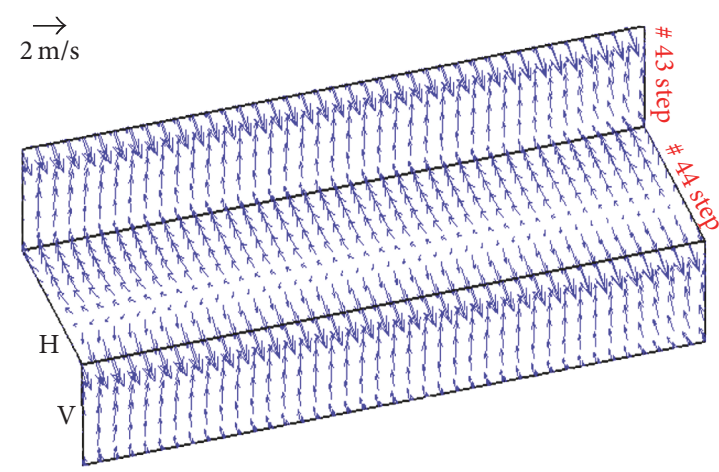

V represents vertical step surface

$\mathrm{H}$ represents horizontal step surface

(a) Velocity vector

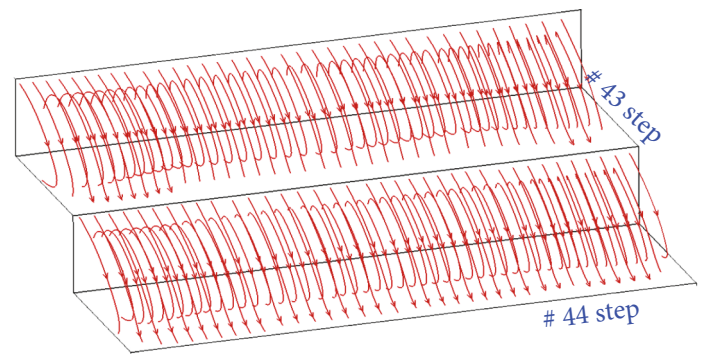

(c) Streamline

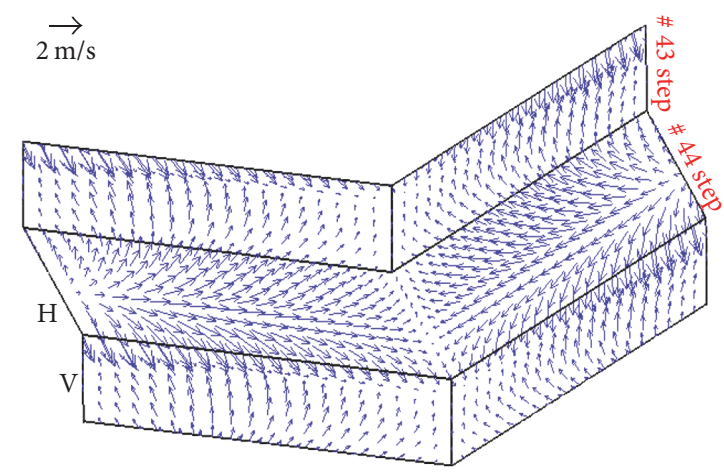

V represents vertical step surface

$\mathrm{H}$ represents horizontal step surface

(b) Velocity vector

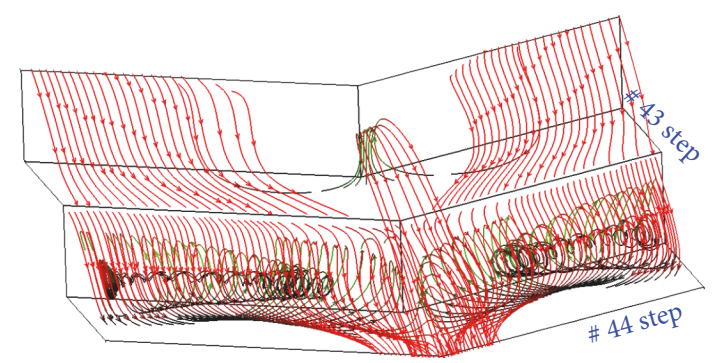

(d) Streamline

FIgURE 7: The velocity vectors and streamlines on steps ((a, c) traditional steps, (b, d) V-shaped steps; Rl $k$ - $\varepsilon$ model).

\section{Notation}

B: $\quad$ Chute width

$h$ : Inlet height of the model

$k$ : Turbulent kinetic energy

$\varepsilon: \quad$ Turbulent kinetic energy dissipation rate

$\alpha_{a}: \quad$ Volume fractions of air

$\alpha_{w}$ : Volume fractions of water

$G_{k}$ : Generation of turbulence kinetic energy

due to the mean velocity gradients

$G_{b}$ : Generation of turbulence kinetic energy due to buoyancy

$u_{i}$ : Mean velocity component in the $i$ th direction

$\mu_{t}$ : Turbulent viscosity

$S_{k}, S_{\varepsilon}$ : User-defined source terms

$\alpha_{k}, \alpha_{\varepsilon}$ : Inverse effective Prandtl numbers

$\nu: \quad$ Turbulent kinematic viscosity

$G_{\omega}: \quad$ Generation of $\omega$

$\Gamma_{k}, \Gamma_{\omega}$ : Effective diffusivity of $k$ and $\omega$, respectively

$Y_{k}, Y_{\omega}$ : Dissipation of $k$ and $\omega$, respectively

$S_{\omega}: \quad$ User-defined source term

$D_{\omega}$ : Cross-diffusion term

$L: \quad$ Width of the step

$H$ : $\quad$ Height of the step

Fr: $\quad$ Froude number.

\section{Conflicts of Interest}

The authors declare that they have no conflicts of interest.

\section{Acknowledgments}

This project was supported by the National Key Research and Development Program of China (no. 2016YFC0401707), the National Natural Science Foundation of China (no. 51579165), and the National Science Fund for Distinguished Young Scholars (no. 51625901). The authors acknowledge the working of Dr. Yong Peng.

\section{References}

[1] A. Amador, M. Sánchez-Juny, and J. Dolz, "Characterization of the nonaerated flow region in a stepped spillway by PIV,' Journal of Fluids Engineering, vol. 128, no. 6, pp. 1266-1273, 2006.

[2] Q. Chen, G. Dai, and H. Liu, "Volume of fluid model for turbulence numerical simulation of stepped spillway overflow," Journal of Hydraulic Engineering, vol. 128, no. 7, pp. 683-688, 2002.

[3] R. M. Sorensen, "Stepped spillway hydraulic model investigation," Journal of Hydraulic Engineering, vol. 111, no. 12, pp. 14611472, 1985.

[4] S. Terrier, M. Pfister, and A. J. Schleiss, "Comparison of chute aerator effect on stepped and smooth spillways," in Proceedings of the 36th IAHR World Congress, vol. 15, pp. 1-5, Hague, The Netherlands, 2015.

[5] E. Aras and M. Berkun, "Comparison of stepped and smooth spillway effects on stream reaeration," Journal of Water SA, vol. 36, no. 3, pp. 309-314, 2010.

[6] M. E. Emiroglu and A. Baylar, "An investigation of effect of stepped chutes with end sill on aeration performance," Water 
Quality Research Journal of Canada, vol. 38, no. 3, pp. 527-539, 2003.

[7] H. Chanson, "Historical development of stepped cascades for the dissipation of hydraulic energy," Trans. Newcomen Soc, vol. 72, no. 2, pp. 295-318, 2001.

[8] H. Chanson and L. Toombes, "Energy dissipation and air entrainment in stepped storm waterway: Experimental study," Journal of Irrigation and Drainage Engineering, vol. 128, no. 5, pp. 305-315, 2002.

[9] N. O. S. Alghazali and S. M. Jasim, "Experimental study on the limits of flow regimes for different configurations of stepped spillway," Civil Environmental Research, vol. 6, no. 6, pp. 30-39, 2014.

[10] O. Kisi, M. E. Emiroglu, and A. Baylar, "Flow regime prediction in stepped channels using neural computing technique," The International Journal of Science \& Technology, vol. 3, no. 1, pp. 109-121, 2008.

[11] Z. C. Zhang, D. Y. Zeng, and A. M. Zheng, "Experimental investigation on the pressure characteristics of skimming flow on stepped chutes," Journal of Hydrodynamics, vol. 18, no. 5, pp. 652-659, 2003.

[12] U. Fratino, M. Sánchez-Juny, B. Valenzano, and M. SánchezJuny, "Air inception and pressure fields in transition flow regime over a stepped spillway," XXX IAHR Congress.

[13] M. Sánchez-Juny, E. Bladé, and J. Dolz, "Analysis of pressures on a stepped spillway," Journal of Hydraulic Research, vol. 46, no. 3, pp. 410-414, 2008.

[14] M. Sánchez-Juny, E. Bladé, and J. Dolz, "Pressures on a stepped spillway," Journal of Hydraulic Research, vol. 45, no. 4, pp. 505511, 2007.

[15] A. Amador, M. Sánchez-Juny, and J. Dolz, "Developing flow region and pressure fluctuations on steeply sloping stepped spillways," Journal of Hydraulic Engineering, vol. 135, no. 12, pp. 1092-1100, 2009.

[16] J. M. Zhang, J. G. Chen, and Y. R. Wang, "Experimental study on time-averaged pressures in stepped spillway," Journal of Hydraulic Research, vol. 50, no. 2, pp. 236-240, 2012.

[17] A. I. Dhatrak and S. P. Tatewar, "Air entrainment and pressure fields over stepped spillway in skimming flow regime," Journal of Power and Energy Engineering, vol. 2, no. 4, pp. 53-57, 2014.

[18] Z. D. Qian, X. Q. Hu, W. X. Huai, and A. António, "Numerical simulation and analysis of water flow over stepped spillways," Science China Technological Sciences, vol. 52, no. 7, pp. 19581965, 2009.

[19] B. Chakib, "Numerical Computation of inception point location for flat-sloped stepped spillway," in Proceeding of the ASME 2013 Heat Transfer Summer Conference Collocated with the ASME 2013, International Conference on Energy Sustainability and the ASME 2013, International Conference on Fuel Cell Science, Engineering and Technology, vol. 2, 2013.

[20] R. Daneshfaraz, A. R. Joudi, A. Ghahramanzadeh, and A. Ghaderi, "Investigation of flow pressure distribution over a stepped spillway," Advances and Applications in Fluid Mechanics, vol. 19, no. 4, pp. 811-822, 2016.

[21] C. W. Hirt and B. D. Nichols, "Volume of fluid (VOF) method for the dynamics of free boundaries," Journal of Computational Physics, vol. 39, no. 1, pp. 201-225, 1981.

[22] B. E. Launder and D. B. Spalding, Lectures in mathematical models of turbulence, Academic Press, London, UK, 1972.

[23] V. Yakhot and S. A. Orszag, "Renormalization group analysis of turbulence. I. basic theory," Journal of Scientific Computing, vol. 1, no. 1, pp. 1-51, 1986.
[24] T.-H. Shih, W. W. Liou, A. Shabbir, Z. Yang, and J. Zhu, "A new $k$ - $\varepsilon$ eddy viscosity model for high reynolds number turbulent flows," Computers and Fluids, vol. 24, no. 3, pp. 227-238, 1995.

[25] D. C. Wilcox, Turbulence Modeling for CFD, DCW Industries, Inc, La Canada, Calif, USA, 1993.

[26] F. R. Menter, "Two-equation eddy-viscosity turbulence models for engineering applications," AIAA Journal, vol. 32, no. 8, pp. 1598-1605, 1994. 


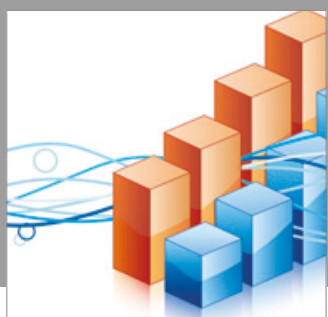

Advances in

Operations Research

vatersals

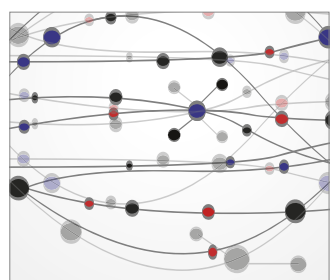

\section{The Scientific} World Journal
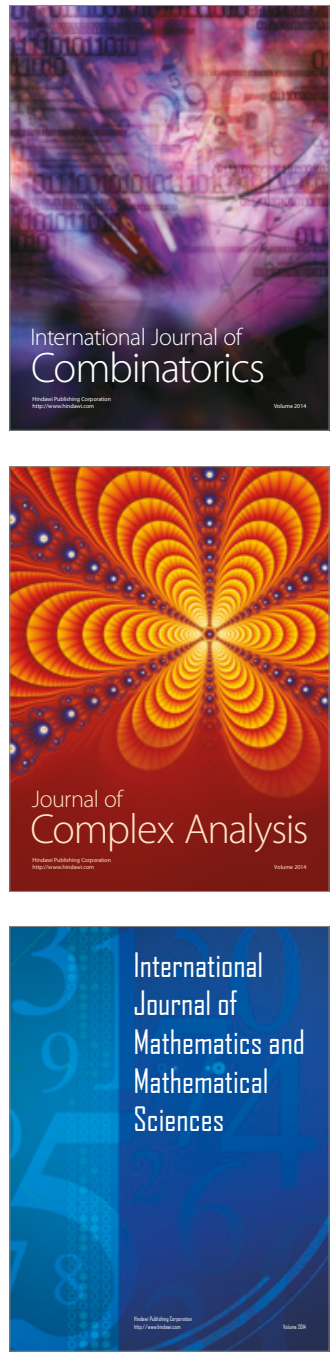
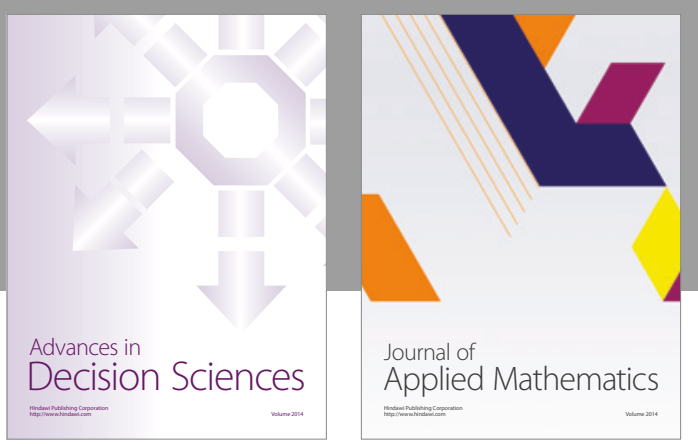

Algebra

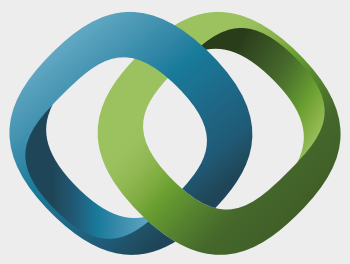

\section{Hindawi}

Submit your manuscripts at

https://www.hindawi.com
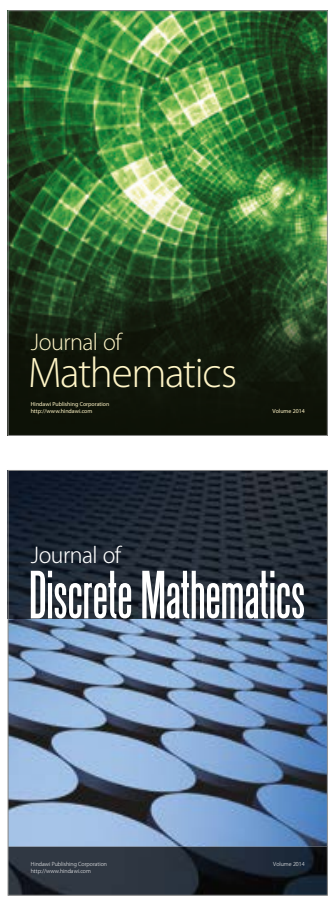

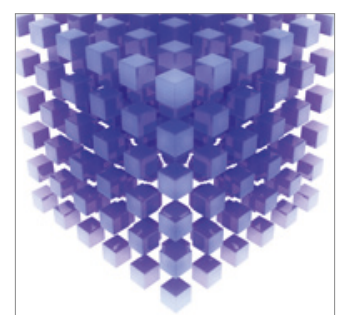

Mathematical Problems in Engineering
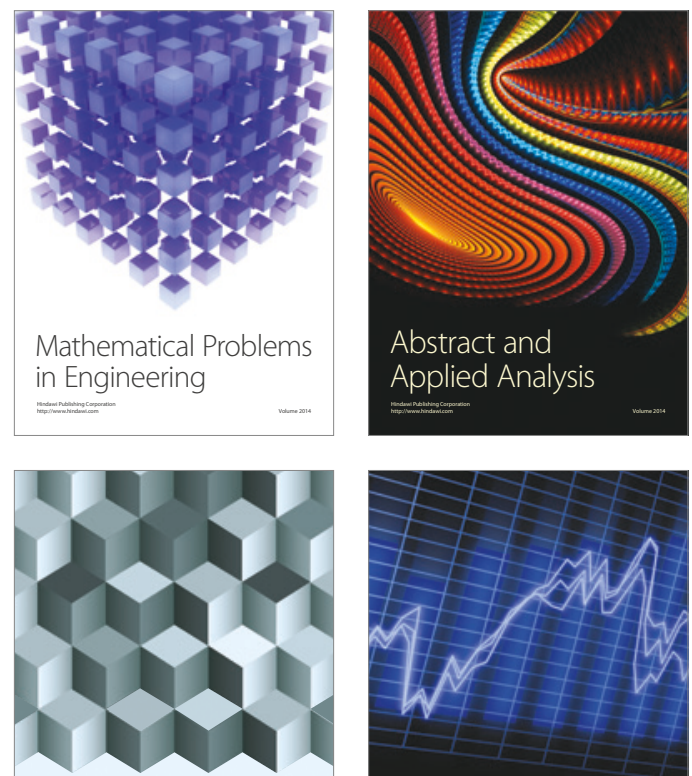

Journal of

Function Spaces

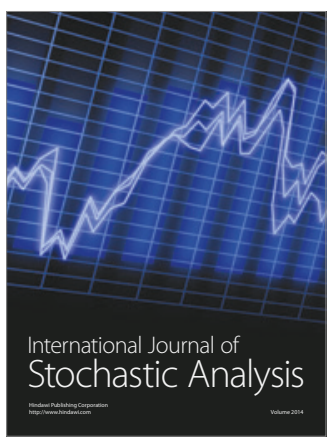

Probability and Statistics
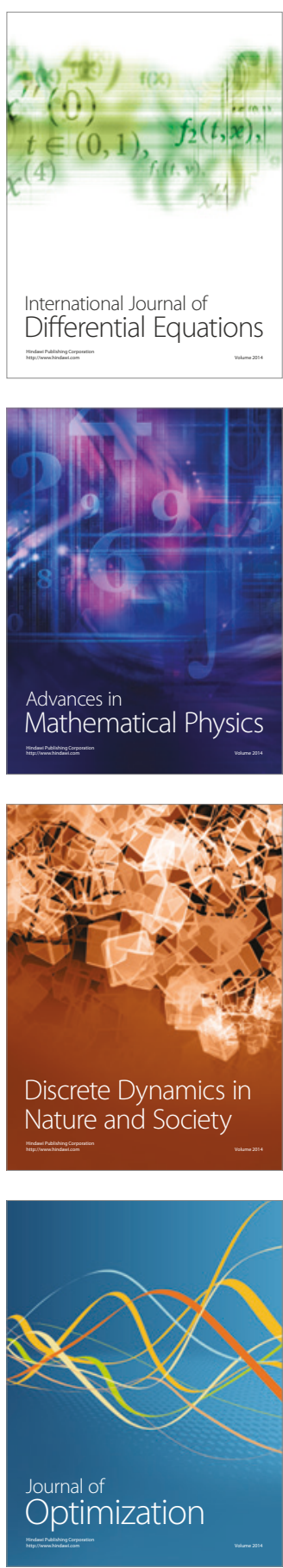